\title{
Reasons for allowing and refusing generic substitution and factors determining the choice of an interchangeable prescription medicine: a survey among pharmacy customers in Finland
}

\author{
Henriikka Nokelainen, Elina Lämsä, Riitta Ahonen and Johanna Timonen * (1)
}

\begin{abstract}
Background: Generic substitution (GS) was introduced in Finland in 2003 and supplemented with a reference price system (RPS) in 2009. Patients play a vital role in the acceptance of GS and the use of less expensive generic medicines. The objective of this study was to explore Finnish pharmacy customers' experience with allowing and refusing GS. Specific aims were to investigate the reasons for (1) allowing and (2) refusing GS and (3) to determine the prescription medicine-related factors influencing the customer's choice of an interchangeable prescription medicine.

Methods: A questionnaire survey was conducted in February 2018. Questionnaires were handed out from 18 community pharmacies across Finland to customers $\geq 18$ years who purchased for themselves a prescription medicine included in the RPS. A descriptive approach was used in the analysis using frequencies, the Chi-square test and Fisher's exact test.

Results: The final study material consisted of 1043 questionnaires (response rate 40.0\%). Of the customers, 47.9\% had both allowed and refused GS, $41.2 \%$ had only allowed GS and $6.0 \%$ had only refused GS. Customers had allowed GS because they wanted to lower their medicine expenses (75.5\%), or because the prescribed medicine (30.8\%) or medicine they had used before (27.4\%) was unavailable at the pharmacy. The main reasons for refusing GS were an insignificant price difference between interchangeable medicines (63.3\%) and satisfaction with the medicine used before (60.2\%). The main factors influencing customers' choice of an interchangeable prescription medicine were price (81.1\%), familiarity (38.4\%) and availability (32.8\%). Customers who had allowed GS chose the medicine based on price. Customers who had only refused GS appreciated familiarity more than the price of the medicine.

Conclusions: GS is a common practice in Finnish community pharmacies. The price of the medicine was the most important factor affecting customers' decision to allow or refuse GS and the choice of an interchangeable prescription medicine. Thus, customers should receive information about medicine prices at the pharmacy in order to help them make their decision. However, individual needs should also be taken into account in counselling because customers regard several factors as important in their choice of an interchangeable medicine.
\end{abstract}

Keywords: Choice of medicine, Community pharmacy, Customer, Experience, Generic substitution, Interchangeable prescription medicine, Reference price system, Survey

\footnotetext{
* Correspondence: johanna.timonen@uef.fi

School of Pharmacy / Social Pharmacy, Faculty of Health Sciences, Kuopio

Campus, University of Eastern Finland, P.O.Box 1627, Fl-70211 Kuopio, Finland
}

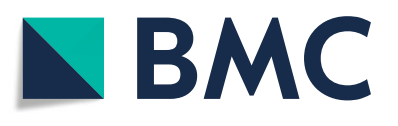

(c) The Author(s). 2020 Open Access This article is distributed under the terms of the Creative Commons Attribution 4.0 International License (http://creativecommons.org/licenses/by/4.0/), which permits unrestricted use, distribution, and reproduction in any medium, provided you give appropriate credit to the original author(s) and the source, provide a link to the Creative Commons license, and indicate if changes were made. The Creative Commons Public Domain Dedication waiver (http://creativecommons.org/publicdomain/zero/1.0/) applies to the data made available in this article, unless otherwise stated. 


\section{Background}

Generic medicines (GM) provide patients with medical treatment that is as effective as brand name products but less expensive [1]. During the last few decades, generic substitution (GS) has become important in promoting the use of less expensive GM. In Europe, GS is in use in over 30 countries [2]. However, there are differences in practices between countries, because GS can be permissive or mandatory, the former being slightly more common. Nevertheless, a physician or a patient can prohibit or decline substitution. GS has been supplemented with a reference price system (RPS) in almost 30 European countries. These systems aim to reduce medicine costs by encouraging the use of less expensive medicines and to increase price competition between pharmaceutical companies $[3,4]$.

Patients play a vital role in the acceptance of GS and the use of less expensive medicines. Patients' attitudes towards GS have been mainly positive [5-7] although some patients are reluctant to substitute their medicines $[6,8,9]$. Refusing GS causes extra costs for both patients and society [10]. Therefore, it is important to understand why patients allow or refuse GS. Many studies have reported that patients allow or would be willing to allow GS based on a physician's $[8,11-13]$ or pharmacist's recommendation $[5,7,8$, $11,12]$ and to lower their medicine expenses $[5,7,8,11$, 14]. Other studies report that patients are reluctant to substitute their medicine because they value a familiar product they have used before or a brand name product they trust $[6,11,14,15]$. It has also been found that negative perceptions regarding the effectiveness and safety of GM make patients less willing to accept a substitute [11, 15-17].

The introduction of GS changes patients' role since they can make the final decision about the prescription medicinal product they choose from generic alternatives at the pharmacy. Consequently, it is important to know which prescription medicine-related factors affect patients' choices in order to develop and provide information for patients to support their decision making. Although a large number of studies have examined GS from different perspectives, only a few have explored prescription medicine-related factors that affect patients' choice of prescription medicine $[8,9$, 18-20].

In Finland, GS was introduced by law in 2003 [21]. The law obliges pharmacists to offer customers the opportunity to substitute their prescription medicines with the cheapest or close to the cheapest interchangeable medicine unless the prescriber prohibits the substitution. The customer can also refuse the substitution. Pharmacists are also required to inform customers about medicine prices and other factors affecting their choice of medicinal product [21]. Since 2016, price counselling has had to include information about the least expensive interchangeable medicine at the point of dispensing [22].
The Finnish Medicines Agency Fimea maintains a list of interchangeable medicines [23]. Interchangeable medicines contain the same quantity of the same active substance, have the same pharmaceutical form (with the exception that tablets and capsules are regarded as interchangeable) and are biologically equivalent; the medicines' safety profiles and therapeutic indexes are also sufficiently broad to permit substitution. At the beginning of 2019, the list of interchangeable medicines consisted of 5429 products, which is about $59 \%$ of all human medicinal products with a marketing authorisation in Finland $(n=9198)$ [24].

In 2009, GS was supplemented with a RPS in which interchangeable medicines are clustered into reference price groups, for each of which a reference price is defined $[25,26]$. The reference price sets limits on the price for which reimbursement is available and is determined by adding $€ 0.50$ to the cheapest interchangeable medicine's retail price [26]. This $€ 0.50$ price difference is called the reference price band. If a customer decides to purchase a prescribed medicine priced higher than the reference price, the reimbursement is calculated from the reference price, and the customer pays the excess in addition to the copayment [27]. Reference price groups, medicinal products included in the groups and reference prices are determined quarterly [26]. However, pharmaceutical companies may update the prices of their products twice a month, so the products included in the price band may vary during each quarter [28].

In Finland, patients' experience with allowing and refusing GS and the factors determining their choice of prescription medicine were investigated in the early stage of GS $[5-7,20]$. Since that time, many legislative reforms have been introduced to promote the use of interchangeable medicines and price competition between pharmaceutical companies, such as the introduction of a RPS in 2009 [25] and greater price counselling at pharmacies in 2016 [22]. The aim of this study was to investigate Finnish pharmacy customers' experience with allowing and refusing GS 15 years after the implementation of GS and after the legislative changes. The specific aims were to investigate the reasons why Finnish pharmacy customers (1) allow or (2) refuse GS and (3) which medicine-related factors affect their decision when choosing an interchangeable prescription medicine.

\section{Methods}

A questionnaire survey was carried out in February 2018. The survey was targeted at pharmacy customers aged $\geq 18$ who were purchasing for themselves a prescription medicine included in the RPS. Questionnaires were distributed from 18 different-sized community pharmacies recruited from all six Regional State Administrative Agencies' areas in mainland Finland: Southern Finland, Southwestern Finland, Western and Central Finland, Eastern Finland, 
Northern Finland, and Lapland [29]. One university pharmacy branch (owned by a university, but operating like a privately-owned pharmacy), one privately-owned big city pharmacy and one privately-owned small rural pharmacy were recruited from each area using convenience sampling. The number of questionnaires delivered to each pharmacy was adapted according to the number of prescriptions dispensed daily at the pharmacy and varied between 30 and 300. Pharmacists were informed about the study in writing. They were requested to tell all eligible customers about the study after the dispensing situation and offer them a questionnaire. Customers filled in the questionnaire at home and mailed it to the researchers. The questionnaires were distributed as long as there were forms left, but for a maximum of 2 weeks. Pharmacists were not required to keep a list of customers who declined to participate. After the study period, the pharmacies reported the number of remaining questionnaires in order to compute the response rate. Altogether, 2606 questionnaires were distributed. Reminders could not be sent because customers were recruited anonymously. A similar method has been successfully used in a few earlier studies targeted at Finnish pharmacy customers [7, 30, 31].

The four-page questionnaire consisted of 21 questions (see Additional file 1). The questionnaire was created for this study and based on earlier Finnish studies [5-7, 20, 31 and on national legislative requirements set for the implementation of GS and RPS [32-34]. The questionnaire was initially tested for face validity by five faculty members with experience of the design of questionnaire surveys. Thereafter, the pilot test was conducted in a local pharmacy. The pilot respondents were interviewed after filling in the questionnaires to check the content validity. Minor revisions were made as a result.

This paper reports the results from five questions regarding patients' decisions to allow or refuse GS, the reasons, and the factors influencing their choice of an interchangeable prescription medicine. The questions regarding the reasons for allowing or refusing GS and the factors influencing the choice of an interchangeable prescription medicine were based on earlier surveys to Finnish medicine users about GS with minor revisions $[5-7,20]$. Respondents' experience with GS was explored by using two structured questions: "Have you ever substituted your prescription medicine with an equivalent medicinal product at the pharmacy?" and "Have you ever chosen not to substitute your prescription medicine with a cheaper equivalent medicinal product offered by the dispenser?". Respondents were instructed to reply "Yes" or "No". Respondents who had allowed or refused GS were asked to specify their reasons using a list of several fixed responses to choose from, and there was also space for a freely worded answer. The factors affecting respondents' choice of prescription medicine were explored with the question: "If your physician has prescribed you a medicine which you can substitute with another, equivalent medicinal product at the pharmacy, which of the following factors matter when you are choosing a prescription medicine at the pharmacy?". The question had a list of several fixed responses to choose from and also space for a freely worded answer. Each respondent's gender, area of residence, education and current use of prescription medicines were obtained using structured questions and the year of birth using an open-ended question.

The data was analysed using the Statistical Package for the Social Sciences software (IBM SPSS Statistics for Windows, Version 25.0. Armonk, NY: IBM Corp). A descriptive approach was used in the analysis using frequencies, percentages and cross-tabulations. The Chi-square test and Fisher's exact test were used to analyse associations between answers and background factors. Statistical significance was determined as $p$-value $<0.05$. In the analysis respondents' ages were placed into one of four groups (18-34, 35-59, 60-74 and 75 years or older).

The study setting and research process complied with local and national ethical instructions for research; this study did not require ethical approval $[35,36]$.

\section{Results}

Altogether 1045 questionnaires were returned, two of which were blank. Consequently, the final study material consisted of 1043 questionnaires, giving a response rate of $40 \%$. Most of the respondents were female $(70.5 \%)$ and $60-74$ years old (45.3\%) (Table 1). The respondents' ages ranged from 18 to 95 years, mean 62.2 (SD 14.9) and median 65 (IQR 16.0) years. There were respondents from all six areas of Finland.

\section{Respondents' experience with GS}

Of the respondents, $47.9 \%$ had both allowed and refused GS, $41.2 \%$ had only allowed GS, and 6\% had only refused GS (Table 2). A small number of respondents (4.9\%) had no experience with GS. Respondents who had no experience with GS were more likely to be aged 18-34 years than those who had experienced GS $(p=0.033)$. Respondents who had only refused GS were more likely to be from Lapland than those who had allowed or had no experience with GS $(p=0.035)$. Respondents who had both allowed and refused GS were less likely to have a basic education qualification than those who had only allowed or only refused GS or had no experience $(p=0.012)$. Instead, they had more often completed vocational education $(p=0.023)$. They were also less likely to use prescription medicines regularly compared to respondents who had only allowed or only refused GS or had no experience ( $p=$ 0.038). Respondents who had only refused GS or had no experience with it were less likely to use prescription 
Table 1 Characteristics of the study respondents $(N=1043)$

\begin{tabular}{|c|c|c|}
\hline & $n$ & $\%$ \\
\hline \multicolumn{3}{|l|}{ Gender $\left(n=1039^{\mathrm{a}}\right)$} \\
\hline Male & 307 & 29.5 \\
\hline Female & 732 & 70.5 \\
\hline \multicolumn{3}{|l|}{ Age in years $\left(n=1007^{\mathrm{a}}\right)$} \\
\hline $18-34$ & 75 & 7.4 \\
\hline $35-59$ & 280 & 27.8 \\
\hline $60-74$ & 456 & 45.3 \\
\hline$\geq 75$ & 196 & 19.5 \\
\hline \multicolumn{3}{|l|}{ Area of residence $\left(n=1030^{a}\right)$} \\
\hline Southern Finland & 184 & 17.9 \\
\hline Southwestern Finland & 78 & 7.6 \\
\hline Western and Central Finland & 251 & 24.4 \\
\hline Eastern Finland & 192 & 18.6 \\
\hline Northern Finland & 242 & 23.5 \\
\hline Lapland & 83 & 8.1 \\
\hline \multicolumn{3}{|l|}{ Education $\left(n=1027^{\mathrm{a}}\right)$} \\
\hline Basic education qualification & 226 & 22.0 \\
\hline Vocational upper secondary qualification or vocational college diploma & 397 & 38.7 \\
\hline Matriculation examination & 117 & 11.4 \\
\hline Lower university degree & 144 & 14.0 \\
\hline Higher university degree & 143 & 13.9 \\
\hline \multicolumn{3}{|l|}{ Current use of prescription medicines $\left(n=1023^{\mathrm{a}}\right)$} \\
\hline Regularly & 606 & 59.2 \\
\hline Temporarily & 102 & 10.0 \\
\hline Both regularly and temporarily & 315 & 30.8 \\
\hline
\end{tabular}

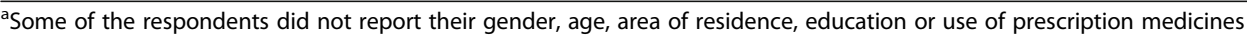

medicines both regularly and temporarily than respondents who had allowed GS $(p=0.004)$.

\section{Reasons for allowing and refusing GS}

The main reason for allowing GS was the respondent's desire to lower medicine expenses (75.5\%) (Table 3). The other common reasons were situations when the prescribed medicine $(30.8 \%)$ or the medicine the respondent had previously used (27.4\%) was unavailable at the pharmacy.

The most common reasons for refusing GS were too small a difference in price between interchangeable medicines $(63.3 \%)$ and the fact that the medicine had been used before and was considered good (60.2\%) (Table 3).

\section{Factors determining the choice of interchangeable prescription medicine}

The three most important factors affecting respondents' choice of interchangeable prescription medicine were price $(81.1 \%)$, familiarity (38.4\%) and availability of the medicine (32.8\%) (Table 4). Respondents who had allowed GS and those who had no experience with GS were more likely to choose the medicine on the basis of price than those who had only refused GS $(p<0.001)$. Furthermore, respondents who had allowed GS and those who had no experience with GS were more likely to choose the medicine based on its availability than those who had only refused GS $(p=0.032)$. In contrast, for respondents who had only refused GS, familiarity with the medicine was the most important factor in their choice of interchangeable prescription medicine compared to other respondents $(p<0.001)$. Furthermore, respondents who had refused GS valued the fact that the medicine was Finnish more often than other respondents $(p=0.014)$.

\section{Discussion}

In this study, a large majority of Finnish pharmacy customers had experienced GS. Almost 90\% had substituted their medicines at least once, and nearly half of those were customers who had only allowed GS. The results indicate that GS is a common practice in Finnish community pharmacies. According to studies conducted in the early stage of GS in Finland, GS represented a 
Table 2 Differences in characteristics as regards respondents' experience with GS ( $N=1043)$

\begin{tabular}{|c|c|c|c|c|c|c|c|c|c|}
\hline \multirow[t]{2}{*}{ Characteristic } & \multicolumn{2}{|c|}{$\begin{array}{l}\text { Respondents who } \\
\text { had only allowed GS }\end{array}$} & \multicolumn{2}{|c|}{$\begin{array}{l}\text { Respondents who } \\
\text { had only refused GS }\end{array}$} & \multicolumn{2}{|c|}{$\begin{array}{l}\text { Respondents who } \\
\text { had both allowed } \\
\text { and refused GS }\end{array}$} & \multicolumn{2}{|c|}{$\begin{array}{l}\text { Respondents who } \\
\text { had no } \\
\text { experience } \\
\text { with GS }\end{array}$} & \multirow[t]{2}{*}{$p$-value } \\
\hline & $\bar{n}$ & $\%$ & $\bar{n}$ & $\%$ & $\bar{n}$ & $\%$ & $\bar{n}$ & $\%$ & \\
\hline All $\left(n=1020^{b}\right)$ & 420 & 41.2 & 61 & 6.0 & 489 & 47.9 & 50 & 4.9 & \\
\hline \multicolumn{10}{|l|}{ Gender $\left(n=1016^{c}\right)$} \\
\hline Male & 114 & 27.3 & 21 & 34.4 & 142 & 29.1 & 20 & 40.0 & 0.228 \\
\hline Female & 303 & 72.7 & 40 & 65.6 & 346 & 70.9 & 30 & 60.0 & 0.228 \\
\hline \multicolumn{10}{|l|}{ Age in years $\left(n=984^{\circ}\right)$} \\
\hline $18-34$ & 39 & 9.5 & 3 & 5.4 & 26 & 5.5 & 7 & 14.6 & 0.033 \\
\hline $35-59$ & 108 & 26.3 & 13 & 23.2 & 148 & 31.6 & 10 & 20.8 & 0.151 \\
\hline $60-74$ & 189 & 46.0 & 31 & 55.4 & 208 & 44.3 & 18 & 37.5 & 0.294 \\
\hline$\geq 75$ & 75 & 18.2 & 9 & 16.1 & 87 & 18.6 & 13 & 27.1 & 0.469 \\
\hline \multicolumn{10}{|l|}{ Area of residence $\left(n=1007^{\circ}\right)$} \\
\hline Southern Finland & 82 & 19.9 & 5 & 8.5 & 88 & 18.1 & 6 & 12.0 & 0.121 \\
\hline Southwestern Finland & 38 & 9.2 & 1 & 1.7 & 35 & 7.2 & 3 & 6.0 & 0.200 \\
\hline Western and Central Finland & 98 & 23.7 & 17 & 28.8 & 112 & 23.1 & 19 & 38.0 & 0.103 \\
\hline Eastern Finland & 69 & 16.7 & 11 & 18.6 & 99 & 20.4 & 9 & 18.0 & 0.566 \\
\hline Northern Finland & 98 & 23.7 & 14 & 23.7 & 112 & 23.1 & 10 & 20.0 & 0.948 \\
\hline Lapland & 28 & 6.8 & 11 & 18.6 & 39 & 8.0 & 3 & 6.0 & 0.035 \\
\hline \multicolumn{10}{|l|}{ Education $\left(n=1005^{\circ}\right)$} \\
\hline Basic education qualification & 98 & 23.7 & 16 & 26.2 & 82 & 17.0 & 16 & 32.0 & 0.012 \\
\hline $\begin{array}{l}\text { Vocational upper secondary } \\
\text { qualification or vocational diploma }\end{array}$ & 146 & 35.4 & 18 & 29.5 & 210 & 43.7 & 17 & 34.0 & 0.023 \\
\hline Matriculation examination & 54 & 13.1 & 8 & 13.1 & 48 & 10.0 & 6 & 12.0 & 0.520 \\
\hline Lower university degree & 67 & 16.2 & 7 & 11.5 & 64 & 13.3 & 6 & 12.0 & 0.524 \\
\hline Higher university degree & 48 & 11.6 & 12 & 19.7 & 77 & 16.0 & 5 & 10.0 & 0.122 \\
\hline \multicolumn{10}{|c|}{ Current use of prescription medicines $\left(n=1000^{c}\right)$} \\
\hline Regularly & 247 & 60.2 & 40 & 66.7 & 273 & 56.6 & 32 & 66.7 & 0.038 \\
\hline Temporarily & 36 & 8.8 & 10 & 16.7 & 47 & 9.8 & 9 & 18.8 & 0.056 \\
\hline Both regularly and temporarily & 127 & 31.0 & 10 & 16.7 & 162 & 33.6 & 7 & 14.6 & 0.004 \\
\hline
\end{tabular}

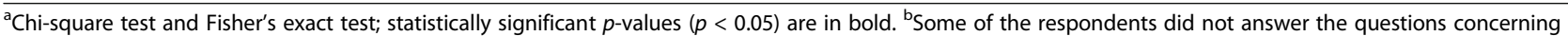
their experience with allowing or refusing GS. 'Some of the respondents did not report their gender, age, area of residence, education or use of prescription medicines

significant pharmaceutical policy reform and had been implemented effectively in practice [38]. Finns look favourably on the opportunity to substitute their medicines and they consider less expensive GM effective and safe $[5,7]$. Positive attitudes towards and experience with GS and less expensive medicines have been shown to increase people's willingness to substitute their medicines $[9,11,12]$. In addition, according to figures published by the Social Insurance Institution of Finland and Finnish statistics on medicines, the number of substitutions has increased and the number of refusals has decreased since 2009 when the RPS was introduced $[39,40]$.

In the present study, a minority of customers had no experience with GS, although the questionnaires were distributed to customers who were purchasing for themselves a prescription medicine included in the RPS. There may be several reasons for this. First, their prescribed medicine had always been the cheapest interchangeable medicine at the point of dispensing. Second, pharmacists did not tell them about the cheaper alternatives and thus did not offer them the opportunity to substitute their prescription medicine. Third, the customer would have been unaware of the substitution if the pharmacist substituted the medicine without asking the customer.

According to this study, there were few differences between pharmacy customers' characteristics and their experience with allowing or refusing GS. Differences mainly 
Table 3 Reasons for allowing and refusing GS

\begin{tabular}{|c|c|c|}
\hline & n & $\%^{\mathrm{a}}$ \\
\hline \multicolumn{3}{|l|}{ Reasons for allowing GS $\left(n=864^{\mathrm{b}}\right)$} \\
\hline Willingness to lower medicine expenses & 652 & 75.5 \\
\hline The prescribed medicine was unavailable at the pharmacy & 266 & 30.8 \\
\hline The previously used medicine was unavailable at the pharmacy & 237 & 27.4 \\
\hline Pharmacist's recommendation & 225 & 26.0 \\
\hline Dissatisfaction with the medicine that was used before & 31 & 3.6 \\
\hline Physician's recommendation & 23 & 2.7 \\
\hline Some other reason ${ }^{c}$ & 39 & 4.5 \\
\hline \multicolumn{3}{|l|}{ Reasons for refusing GS $\left(n=528^{\mathrm{d}}\right)$} \\
\hline Too small a difference in price of the interchangeable medicines & 334 & 63.3 \\
\hline Satisfaction with the medicine used before & 318 & 60.2 \\
\hline The interchangeable medicine that the customer wanted was unavailable at the pharmacy & 72 & 13.6 \\
\hline Customer's concern that the interchangeable medicine will be less effective than the medicine used before & 67 & 12.7 \\
\hline Choice of interchangeable medicine was made during physician visit & 59 & 11.2 \\
\hline Too many switches before a suitable one was found & 48 & 9.1 \\
\hline Customer's concern that the interchangeable medicine will be less effective than the one prescribed by the physician & 42 & 8.0 \\
\hline Customer's medicines are subject to special reimbursement ${ }^{\mathrm{e}}$, so the customer would not have benefited from the saving & 26 & 4.9 \\
\hline Customer did not receive enough information about different alternative products & 22 & 4.2 \\
\hline Fear of mixing up medicines & 15 & 2.8 \\
\hline Some other reason ${ }^{f}$ & 72 & 13.6 \\
\hline
\end{tabular}

${ }^{a}$ Respondents may have chosen several options

${ }^{b}$ Only customers who had experience with allowing GS answered this question. However, some did not report reasons for allowing GS

${ }^{C}$ E.g. willingness to purchase a Finnish product, the medicine was substituted in order to receive full reimbursement, and the previously used medicine was no longer manufactured

${ }^{d}$ Only customers who had experience with refusing GS answered this question. However, some did not report reasons for refusing GS

e In Finland, reimbursements for medicines are divided into three rates: basic reimbursement ( $40 \%$ of the prescription medicine price), lower special reimbursement $(65 \%)$ and higher special reimbursement (100\%, the customer pays a $€ 4.50$ co-payment per prescription medicine purchase) [37]

${ }^{\mathrm{f}} \mathrm{E}$.g. the cost of the medicine is not paid by the customer, willingness to purchase a Finnish product, handy packet, and customer's experience or fear of side effects

occurred among those who had both allowed and refused GS. Interestingly, pharmacy customers from Lapland were more likely to refuse GS than customers from other areas. This may result from the fact that there are differences in morbidity between Lapland and other regions of Finland [41], and some patient groups may refuse GS more often than others [42, 43]. However, we did not ask customers to specify their medications in this survey and we are therefore unaware of what medicines they refused to substitute. Further studies on this are needed in the future. It is also possible that the result is biased by the small number of respondents from Lapland. In contrast to some previous studies, gender was not associated with GS experience in our study $[12,44]$.

In this study, GS was mainly allowed by pharmacy customers because they wanted to lower their medicine expenses, which is in line with earlier studies conducted in Finland $[5,7]$ and other countries $[8,11,14,44]$. The other main reasons for allowing GS were related to the unavailability of the prescribed medicine, which was an interesting finding. The current study showed that the unavailability of a prescribed medicine has become a more common reason to change to another interchangeable medicine (30.8\%) compared to a Finnish population survey conducted 10 years earlier in which this reason was reported by $19.6 \%$ of participants [5]. This study did not reveal the reasons behind this finding, but possible reasons can be discussed. Nowadays, the number of medicinal products eligible for substitution is large [24] and it is impossible for pharmacies to stock all alternatives. A prescription medicine could also have been unavailable because it was in short supply. A previous study has reported that medicine shortages are common in community pharmacies in Finland because the large majority of pharmacies suffer from medicine shortages daily or almost daily [45]. According to figures published by the Finnish Medicines Agency, the number of medicine shortages reported by marketing authorization holders has tripled in Finland since 2012 [46]. However, medicine shortages seldom cause problems at pharmacies because GS enables pharmacists to substitute the customer's medicine with an 
Table 4 Factors that matter when respondents choose an interchangeable prescription medicine $(N=1043)$

\begin{tabular}{|c|c|c|c|c|c|c|c|c|c|c|c|}
\hline & \multicolumn{2}{|c|}{$\begin{array}{l}\text { All } \\
\left(n=1030^{\mathrm{a}}\right)\end{array}$} & \multicolumn{2}{|c|}{$\begin{array}{l}\text { Respondents } \\
\text { who had only } \\
\text { allowed GS } \\
\left(n=417^{a, b}\right)\end{array}$} & \multicolumn{2}{|c|}{$\begin{array}{l}\text { Respondents } \\
\text { who had only } \\
\text { refused GS } \\
\left(n=60^{\mathrm{a}, \mathrm{b}}\right)\end{array}$} & \multicolumn{2}{|c|}{$\begin{array}{l}\text { Respondents } \\
\text { who had both } \\
\text { allowed and } \\
\text { efused GS } \\
\left(n=486^{a, b}\right)\end{array}$} & \multicolumn{2}{|c|}{$\begin{array}{l}\text { Respondents who } \\
\text { had no experience } \\
\text { with GS } \\
\left(n=47^{\mathrm{a}, \mathrm{b}}\right)\end{array}$} & \multirow[t]{2}{*}{$p$-value } \\
\hline & $\bar{n}$ & $\%^{c}$ & $\bar{n}$ & $\%^{c}$ & $\mathrm{n}$ & $\%^{c}$ & $\mathrm{n}$ & $\%^{c}$ & $\bar{n}$ & $\%^{c}$ & \\
\hline Price of the medicine & 835 & 81.1 & 374 & 89.7 & 28 & 46.7 & 386 & 79.4 & 33 & 70.2 & $<0.001$ \\
\hline Familiarity with the medicine & 396 & 38.4 & 108 & 25.9 & 41 & 68.3 & 221 & 45.5 & 19 & 40.4 & $<0.001$ \\
\hline Availability of the medicine & 338 & 32.8 & 135 & 32.4 & 11 & 18.3 & 174 & 35.8 & 12 & 25.5 & 0.032 \\
\hline The medicine is Finnish & 198 & 19.2 & 63 & 15.1 & 14 & 23.3 & 111 & 22.8 & 6 & 12.8 & 0.014 \\
\hline Opportunity to halve the tablet & 190 & 18.4 & 74 & 17.7 & 14 & 23.3 & 93 & 19.1 & 6 & 12.8 & 0.524 \\
\hline Medicine pack & 166 & 16.1 & 60 & 14.4 & 6 & 10.0 & 89 & 18.3 & 6 & 12.8 & 0.193 \\
\hline Excipients contained in the product & 131 & 12.7 & 32 & 7.7 & 4 & 6.7 & 90 & 18.5 & 3 & 6.4 & $<0.001$ \\
\hline $\begin{array}{l}\text { Manufacturer of the medicine / } \\
\text { pharmaceutical company }\end{array}$ & 59 & 5.7 & 12 & 2.9 & 11 & 18.3 & 35 & 7.2 & 1 & 2.1 & $<0.001$ \\
\hline Tablet/capsule shape & 59 & 5.7 & 17 & 4.1 & 4 & 6.7 & 37 & 7.6 & 1 & 2.1 & 0.097 \\
\hline $\begin{array}{l}\text { Product name / brand / name } \\
\text { of the medicine }\end{array}$ & 14 & 1.4 & 1 & 0.2 & 3 & 5.0 & 10 & 2.1 & 0 & 0.0 & 0.007 \\
\hline Tablet/capsule colour & 11 & 1.1 & 3 & 0.7 & 0 & 0.0 & 7 & 1.4 & 1 & 2.1 & 0.438 \\
\hline Other reason ${ }^{e}$ & 35 & 3.4 & 10 & 2.4 & 5 & 8.3 & 16 & 3.3 & 4 & 8.5 & 0.025 \\
\hline
\end{tabular}

${ }^{\mathrm{a}}$ Some of the respondents did not answer the question concerning the factors that affected their choice of an interchangeable prescription medicine. ${ }^{\mathrm{b}}$ Some of

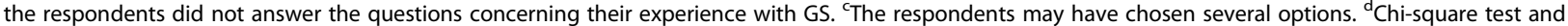
Fisher's exact test; statistically significant $p$-values $(p<0.05)$ are in bold. ${ }^{e}$ E.g. recommendation or opinion of the physician or pharmacist

available interchangeable product [45]. Nevertheless, this finding would be an interesting topic to study in the future.

According to this study, the main reasons for refusals were too small a price difference between interchangeable medicines and satisfaction with the medicine used before. Our results differ from previous Finnish studies in that nowadays an insignificant price margin is a more common reason for refusing GS than in the early stages of GS (63.3\% versus 19 and 35\%) [6, 7]. In Finland, the price band has been narrowed twice from $€ 3$ to $€ 0.5$ during 20092017 [4, 47]. Consequently, it is possible that the $€ 0.50$ price band is already so narrow that it is an insufficient incentive for some customers to substitute their medicine.

In contrast to earlier Finnish studies [5, 7], our results indicate that customers are not as dependent on the pharmacist's or physician's opinion in their decision to allow or refuse GS than in the early stage of GS. In many earlier studies, the pharmacist's or physician's recommendations were among the main reasons why customers allowed GS or were more willing to accept GS in the future $[5,7,8,11-$ 13]. In Finland, at the beginning of the GS reform [6, 7], patients wanted to ask their physician's opinion before they allowed GS or they had already chosen the product at the physician's office and then refused the substitution at the pharmacy [6]. It now seems that GS practice is familiar to customers and they can make their decisions by themselves.

This study found that a large majority of pharmacy customers choose their interchangeable prescription medicine based on price. The same finding emerged from a survey conducted 10 years earlier in Finland [20]. However, there were some differences in the factors affecting the choice of medicine in terms of pharmacy customers' experience with GS. Customers who had allowed GS and customers who had no experience with GS considered price the most important factor in their choice of medicine. In contrast, customers who had only refused GS considered familiarity more important than price in their choice of medicine. Nonetheless, our results highlight the importance of price information in GS situations at pharmacies as a way of supporting customers' decision making. In addition, because pharmacy customers appreciate different factors in their choice of interchangeable medicine, pharmacies should also give information about such factors. In Finland, pharmacists are required by law to inform customers not just about medicine prices but also about other factors affecting the choice of medicinal product $[21,22]$. In the future, it would be interesting to study how patient counselling related to interchangeable medicines and GS is practised in pharmacies and to determine whether counselling meets the legal requirements. This should be studied from the perspective of pharmacists and pharmacy customers.

\section{Strengths and limitations}

This study has some strengths and limitations. The study method was suitable for reaching the target group, i.e. customers who had experience with GS because questionnaires 
were distributed to customers who were purchasing for themselves prescription medicines included in the RPS. The study sample was also large, involving pharmacy customers across mainland Finland. The response rate of $40 \%$ is typical for this kind of method where it was impossible to send reminders $[7,29,30]$. There are no comparable statistics on Finnish pharmacy customers' characteristics. Pharmacists were instructed to offer the questionnaire to all eligible customers, but they still may have used convenience sampling. Because customers were recruited anonymously, no information was gained about the characteristics of the customers to whom the questionnaire was offered but who declined to participate or who did not return the questionnaire. Compared to the statistics of Finnish population groups who have received reimbursement for medicine costs under the Health Insurance Scheme [48], men and customers aged 18-34 and 60-74 were under-represented in the present study. This may result from the fact that women and older people tend to respond to surveys more than men and younger adults $[49,50]$. However, our study respondents' current use of prescription medicines, gender and age distributions were similar to those of earlier Finnish studies conducted among pharmacy customers with similar methods [7, 31]. Accordingly, we suggest that the findings of this study can be generalized, with caution, to customers purchasing their prescription medicines at Finnish community pharmacies.

The majority of the questions reported in this paper were based on earlier Finnish population surveys [5, 6, 20] and a survey of Finnish pharmacy customers [7]. The questionnaire was tested for face validity and content validity before the survey. Furthermore, the separate response rates for the questions reported in this paper were 95-99\%, illustrating that the respondents found the questions understandable.

\section{Conclusions}

GS is a common practice in Finnish community pharmacies. A large majority of pharmacy customers have experience with allowing GS and half of customers have experience with refusing it. Pharmacy customers allow GS because they want to lower their medicine expenses. However, when the price difference between interchangeable medicines is too small, customers more frequently refuse GS. Also, some customers want to use familiar medicines and therefore refuse substitution. The most important factor affecting the customer's choice of interchangeable medicine is price. It is therefore important that customers receive information about medicine prices at the pharmacy in order to support their decision making in the GS situation. However, individual needs should also be taken into account in counselling because customers appreciate several other factors in their choice of an interchangeable medicine.

\section{Supplementary information}

Supplementary information accompanies this paper at https://doi.org/10. 1186/s12913-020-4894-3.

Additional file 1. The questionnaire used in the current study. Survey for pharmacy customers regarding generic substitution and selection of prescription medicines

\section{Abbreviations}

GM: Generic medicines; GS: Generic substitution; RPS: Reference price system

\section{Acknowledgements}

The authors would like to thank the study pharmacies that distributed the questionnaires.

\section{Authors' contributions}

$J T, R A$ and EL participated in designing the study and collecting the data. $\mathrm{HN}$ conducted the data analysis and drafted the first version of the manuscript. EL and JT helped with data analysis. All Authors participated in discussing the findings, contributed to the critical revision of the manuscript, and read and approved the final manuscript.

\section{Funding}

This study was funded by The Social Insurance Institution of Finland (Kela). Kela had no role in the study design, data collection, data analysis, data interpretation or writing of the manuscript. The opinions expressed in this paper are those of the authors and do not reflect the official position of Kela.

\section{Availability of data and materials}

The datasets used and analysed during the current study are not publicly available, but are available from the corresponding author upon reasonable request.

\section{Ethics approval and consent to participate}

The study setting and research process were in compliance with local and national ethical instructions for research $[35,36]$. According to the guidelines prepared by the National Advisory Board on Research Ethics (TENK), this study required no ethical approval, because an ethical review is not required for this type of human sciences research in Finland [35]. Participation in this study was voluntary and answering the questionnaire and mailing it to the researchers was regarded as informed consent to participate in the survey [35].

\section{Consent for publication}

Not applicable.

Competing interests

The authors declare that they have no competing interests.

Received: 22 June 2019 Accepted: 7 January 2020

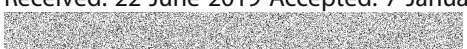

\section{References}

1. The Finnish Medicines Agency Fimea. Generic products and generic substitution. 2019. https://www.fimea.fi/web/en/for_public/generic_ products_and_generic_substitution. Accessed 4 Mar 2019.

2. WHO Regional Office for Europe. Medicines reimbursement policies in Europe. 2018. www.euro.who.int/en/publications/abstracts/medicinesreimbursement-policies-in-europe. Accessed 6 Feb 2019.

3. Finnish Government. Government proposal 165. 2002. https://www.finlex.fi/ fi/esitykset/he/2002/20020165. Accessed 11 Mar 2019. (in Finnish).

4. Finnish Government. Government proposal 100. 2008. https://www.finlex.fi/ fi/esitykset/he/2008/20080100. Accessed 11 Feb 2019. (in Finnish).

5. Heikkilä R, Mäntyselkä $P$, Ahonen R. Do people regard cheaper medicines effective? Population survey on public opinion of generic substitution in Finland. Pharmacoepidemiol Drug Saf. 2011;20:185-91.

6. Heikkilä R, Mäntyselkä $P$, Ahonen R. Why people refuse generic substitution: a population survey of public opinion on generic substitution in Finland. Drugs Ther Perspect. 2012;28(8):24-6. 
7. Heikkilä R, Mäntyselkä P, Hartikainen-Herranen K, Ahonen R. Customers' and physicians' opinions of and experiences with generic substitution during the first year in Finland. Health Policy. 2007;82:366-74.

8. Skaltsas LN, Vasileiou KZ. Patients' perceptions of generic drugs in Greece. Health Policy. 2015;119:1406-14.

9. Salmane Kulikovska I, Poplavska E, Ceha M, Mezinska S. Use of generic medicines in Latvia: awareness, opinions and experiences of the population. J Pharm Policy Pract. 2019;12:1.

10. Martikainen J, Kiviniemi V, Oravilahti T, Enlund H, Happonen P. Lääkkeen vaihdon kieltäminen aiheuttaa merkittäviä kustannuksia. Suom Lääkäril. 2016;71:1544-6 (in Finnish)

11. Babar ZU, Stewart J, Reddy S, Alzaher W, Vareed P, Yacoub N, et al. An evaluation of consumers' knowledge, perceptions and attitudes regarding generic medicines in Auckland. Pharm World Sci. 2010;32:440-8.

12. Kobayashi E, Karigome H, Sakurada T, Satoh N, Ueda S. Patients' attitudes towards generic drug substitution in Japan. Health Policy. 2011;99:60-5.

13. Quintal C, Mendes P. Underuse of generic medicines in Portugal: an empirical study on the perceptions and attitudes of patients and pharmacists. Health Policy. 2012;104:61-8.

14. Sharrad AK, Hassali MA. Consumer perception on generic medicines in Basrah, Iraq: preliminary findings from a qualitative study. Res Social Adm Pharm. 2011;7:108-12.

15. Håkonsen $H$, Toverud EL. Special challenges for drug adherence following generic substitution in Pakistani immigrants living in Norway. Eur J Clin Pharmacol. 2011;67:193-201.

16. Rathe J, Larsen P, Andersen M, Paulsen M, Jarbøl D, Thomsen J, et al. Associations between generic substitution and patients' attitudes, beliefs and experiences. Eur J Clin Pharmacol. 2013:69:1827-36.

17. O'Leary A, Usher C, Lynch M, Hall M, Hemeryk L, Spillane S, et al. Generic medicines and generic substitution: contrasting perspectives of stakeholders in Ireland. BMC Res Notes. 2015;8:790

18. Toklu HZ, Dülger GA, Hidiroğlu S, Akici A, Yetim A, Gannemoğlu HM, et al. Knowledge and attitudes of the pharmacists, prescribers and patients towards generic drug use in Istanbul - Turkey. Pharm Pract (Granada). 2012; 10(4):199-206

19. Drozdowska A, Hermanowski T. Predictors of generic substitution: the role of psychological, sociodemographic, and contextual factors. Res Social Adm Pharm. 2016:12:119-29.

20. Heikkilä R, Mäntyselkä P, Ahonen R. Price, familiarity, and availability determine the choice of drug - a population-based survey five years after generic substitution was introduced in Finland. BMC Clin Pharmacol. 2011; 11:20.

21. Medicine Act 80/2003. https://www.finlex.fi/fi/laki/alkup/2003/20030080. Accessed 8 Feb 2019. (in Finnish)

22. Finnish Government. Government proposal 330. 2014. https://www.finlex.fi/ fi/esitykset/he/2014/20140330. Accessed 11 Mar 2019. (in Finnish)

23. The Finnish Medicines Agency Fimea. Criteria used in compiling the list. 2019. https://www.fimea.fi/web/en/databases_and_registeries/substitutable_ medicinal_products/criteria_used_in_compiling_the_list. Accessed 8 Feb 2019.

24. The Finnish Medicines Agency Fimea. Vaihtokelpoisten lääkevalmisteiden luettelo 1.1-31.3.2019. 2019. www.fimea.fi/-/vaihtokelpoistenlaakevalmisteiden-luettelo-1-1-31-3-2019. Accessed 30 Jan 2019. (in Finnish).

25. Medicine Act 803/2008. https://www.finlex.fi/fi/laki/alkup/2008/20080803. Accessed 8 Feb 2019. (in Finnish)

26. Health Insurance Act 1224/2004. https://www.finlex.fi/fi/laki/kaannokset/2 004/en20041224_20110911.pdf. Accessed 8 Feb 2019.

27. The Social Insurance Institution of Finland. Rates of reimbursement. 2017. https://www.kela.fi/web/en/reimbursements-for-medicine-expences-amount Accessed 8 Apr 2019.

28. The Social Insurance Institution of Finland. Generic substitution and the reference price system. 2018. www.kela.fi/web/en/medicine-expensesgeneric-substitution-and-the-reference-price-system. Accessed 30 Jan 2019

29. Regional State Administrative Agencies. Toimialueet. https://www.avi.fi/web/ avi/toiminta-alue. Accessed 16 Oct 2019

30. Tiihonen $\mathrm{M}$, Heikkinen A-M, Leppänen H-M, Ahonen R. Information sources used by women in Finland who use hormonal contraceptives. Pharm World Sci. 2010:32:66-72

31. Lämsä E, Timonen J, Ahonen R. Pharmacy Customers' Experiences With Electronic Prescriptions: Cross-Sectional Survey on Nationwide Implementation in Finland. J Med Internet Res. 2018;20(2):e68.
32. Finnish Medicine Act 395/1987. https://www.finlex.fi/fi/laki/ajantasa/1987/1 9870395. Accessed 8 Feb 2019. (in Finnish).

33. Decree on the prescription of medicines 1088/2010. https://www.finlex.fi/fi/ laki/alkup/2010/20101088. Accessed 8 Feb 2019. (in Finnish).

34. The Finnish Medicines Agency Fimea. The regulation on dispensing medicines. 2016. https://www.fimea.fi/documents/160140/764653/M\%C3\% A4\%C3\%A4r\%C3\%A4ys.pdf/9332fa84-d115-41e2-b357-19eb28191312. Accessed 8 Feb 2019. (in Finnish).

35. Finnish Advisory Board on Research Integrity. Ethical review in human sciences. 2019. https://www.tenk.fi/en/ethical-review-in-human-sciences. Accessed 24 Apr 2019.

36. University of Eastern Finland. Instructions and forms. 2019. www.uef.fi/en/ web/guest/research/instructions-and-forms. Accessed 30 Jan 2019.

37. The Social Insurance Institution of Finland. Reimbursements for medicine expenses. 2018. https://www.kela.fi/web/en/medicine-expenses. Accessed 8 Feb 2019

38. Timonen J, Heikkilä R, Ahonen R. Generic substitution in Finland: lessons learned during 2003-2008. J Pharm Health Serv Res. 2013;4:165-72.

39. The Social Insurance Institution of Finland. Lääkevaihto ja viitehintajärjestelmä 2003-2009, 2013-2018. https://www.kela.fi/laakkeet_ laakevaihto-ja-viitehintajarjestelma. 2018. Accessed 18 Apr 2019. (in Finnish).

40. The Finnish Medicines Agency Fimea and Social Insurance Institution of Finland. Finnish statistic of medicines 2012. Helsinki: The Finnish medicines agency Fimea and social insurance institution; 2013. http://www.julkari.fi/ handle/10024/130848. Accessed 4 Mar 2019

41. National Institute For Health and Welfare. THL's Morbidity Index. 2018 http://www.terveytemme.fi/sairastavuusindeksi/index.html. Accessed 5 Mar 2019. (in Finnish).

42. Paldán M. Refusal of generic substitution by pharmacy customers - a register-based study. Master's thesis. Kuopio: University of Kuopio, Faculty of Pharmacy; 2006. (in Finnish)

43. The Finnish Medicines Agency Fimea and Social Insurance Institution of Finland. Finnish statistics of medicines 2009. Helsinki: The Finnish medicines agency Fimea and social insurance institution; 2010. http://www.julkari.fi/ handle/10024/130851. Accessed 5 Mar 2019

44. Decollogny A, Eggli Y, Halfon P, Lufkin TM. Determinants of generic drug substitution in Switzerland. BMC Health Serv Res. 2011:11:17.

45. Heiskanen K, Ahonen R, Karttunen P, Kanerva R, Timonen J. Medicine shortages - a study of community pharmacies in Finland. Health Policy. 2015:119:232-8

46. Sarnola K. Availability and accessibility of medicines. A study of medicine shortages in Finland and accessibility of orphan medicines in Europe. Publications of the University of Eastern Finland, Dissertations in Health Sciences 470. Kuopio: Faculty of Health Sciences, University of Eastern Finland; 2018

47. Finnish Government. Government proposal. 2016. https://www.finlex.fi/fi/ esitykset/he/2016/20160184. Accessed 11 Feb 2019. (in Finnish).

48. Finnish Medicines Agency Fimea and Social Insurance Institution. Finnish Statistics on Medicines 2017. Helsinki: The Finnish medicines agency Fimea and social insurance institution; 2018. https://www.julkari.fi/handle/10024/13 7174. Accessed 16 Oct 2019

49. Tolonen $\mathrm{H}$. Towards the high quality of population surveys. Standardization and quality control. Publications of the national public health institute A27/ 2005. Helsinki: National Public Health Institute Helsinki and Faculty of Medicine, University of Kuopio; 2006.

50. Silvennoinen $\mathrm{E}$, Hämeen-Anttila K, Jauhonen H-M, Jyrkkä J. Fimea medicines barometer 2017. Description of the data and data collection of population surveys. Serial Publication Fimea Develops, Assesses and Informs 12/2018. Helsinki: Finnish Medicines Agency Fimea; 2018.

\section{Publisher's Note}

Springer Nature remains neutral with regard to jurisdictional claims in published maps and institutional affiliations. 